\title{
Finite Element Modeling of Correlating Mechanical Properties with Erosion Wear Rate
}

\author{
Bing $\mathrm{Wu}$, Fengfang $\mathrm{Wu}^{*}$ and Jinjie $\mathrm{Li}$ \\ School of Mechanical Engineering Shandong University, Key Laboratory of High-efficiency and Clean Mechanical Manufacture \\ (Shandong University) Ministry of Education, Jinan, 250061, China \\ ${ }^{*}$ Corresponding author
}

\begin{abstract}
A finite element display dynamic model was developed to study mechanical properties of single layer coatings under single solid particle impact, simulating particulate erosion conditions. Four coatings on the same material substrate material were analyzed to determine reduction in additional factors influence. The model was used to study the effect of mechanical characteristics such as microhardness, elastic modulus and combination of microhardness and elastic modulus. The result shows that erosion rate of the coatings decreased with an increase of the ratio $\mathrm{H}^{3} / \mathrm{E}^{2}$ and $\mathrm{H} / \mathrm{E}$.
\end{abstract}

Keywords—component; fem; mechanical properties; erosion

\section{INTRODUCTION}

In many cases, application of protective coatings appears to be the most cost effective option to date ${ }^{[1,2]}$. But the traditional methods of developing protective coatings through trial-anderror experimentation are time consuming and costly. Finite element (FE) based numerical simulation can be used as a time and cost effective tool to estimate the erosion behavior of components exposed to slurry erosion under different erosion conditions with a limited number of experiments if a suitable erosion mechanism is implemented.

Chen ${ }^{[3]}$ indicated that the surface damage by solid-particle erosion depends on many factors, including the impact velocity, particle size and shape of the erodent, mechanical properties of both the target material and the erodent, and the volume fraction, size and properties of the reinforcing phase as well as the bonding between the matrix and the reinforcing phase. Following these observations it was decided to investigate, initial results are reported on FE modeling of brittle coating response to a single spherical particle impact in the present paper. Finally the erosion rate the four coatings on the same substrate will be test to verify this Finite element modeling.

\section{EXPERIMENTAL SET-UP}

WC/Co hard alloy was used as substrate materials. Four coatings, TiN, CrAlTiN, CrAlN and TiAlN were produced by pulsed filtered vacuum cathode arc deposition assisted with ion bombardment. The microhardness of the coating was measured by MH- 6 vickers microhardness tester. In this test, the head load $(0.25 \mathrm{~N})$ was selected to eliminate the influence of the microhardness of the substrate material. The time was spent at each point of this test is $5 \mathrm{~s}$, Five points for each sample were measured and take the average. The results were given in Table
I. The elastic modulus of the coating was measured by swiss CSEM nanoindentation instrument. The test results are shown in Table I.

TABLE I. STYLES EROSION MODEL

\begin{tabular}{|l|l|l|l|}
\hline Substrate & Coating & Microhardness/GPa & $\begin{array}{c}\text { Elastic } \\
\text { Modulus/GPa }\end{array}$ \\
\hline WC/Co & TiN & 23.16 & 483 \\
\hline WC/Co & TiAlN & 31.60 & 580 \\
\hline WC/Co & CrAlN & 28.90 & 468 \\
\hline WC/Co & CrAlTiN & 20.04 & 340 \\
\hline
\end{tabular}

The equipment used for this erosion wear test is gas sandblast erosion equipment. The maximum depth of the coating eroded pit is used as the erosion wear of the coating, and the erosion wear rate was calculated as the depth of wear of the coating per unit time increased. The contour of the etched pit was measured with a veeco NT9300 optical profiler

\section{FinIte ELEMENT Formulation}

\section{A. Erosion Wear Equation}

According to the theory of indentation fracture mechanics, the coating volume removed by a single erosion particle can be calculated as (1) by $\mathrm{wu}^{[4]}$.

$$
K_{I c}=C_{k} \frac{H^{3}}{E^{2}}
$$

Where $K_{I c}, H, C_{k}$ and $E$ is coating fracture toughness, microhardness, constant, and elastic modulus. And Ann's research results showed that as the value increase, the crack resistance of the coating increasing ${ }^{[5]}$. So we can assume:

$$
d V=\frac{f_{1}}{C_{k}} \frac{E^{3 / 2}}{H^{9 / 4}}\left(\frac{E^{7 / 4} U^{5 / 12}}{H^{23 / 12}}-\frac{C_{k} f_{2}}{U_{k i n}^{1 / 12}}\right)
$$

Where $V$ is the erosion volume, $f_{1}$ and $f_{2}$ is the dimensionless constant, which reflects the effect of experimental condition parameters. 
During the erosion process, the material is subjected to the impact of high-speed erosion particles, which will generate large deformations. The application of the explicit dynamics algorithm to the problems of high-pressure and high-strain rates for such materials will achieve more satisfactory results. The finite element based on commercial code ABAQUS/Explicit. Explicit kinetic equations ${ }^{[6]}$ is given by:

$$
M \ddot{u}=P-I
$$

Where $\mathrm{M}$ is the quality of the node, $u$ is node acceleration, $\mathrm{P}$ is applied external force, $\mathrm{I}$ is internal force.

At the beginning of the incremental step, the calculated acceleration is given by:

$$
\left.\ddot{u}\right|_{(t)}=\left.(M)^{-1}(P-I)\right|_{(t)}
$$

For the integration of acceleration over time, the center difference method is needed:

$$
\left.\dot{u}\right|_{\left(t+\frac{\Delta t}{2}\right)}=\left.\dot{u}\right|_{\left(t-\frac{\Delta t}{2}\right)}+\left.\frac{\left.\Delta t\right|_{(t+\Delta t)}+\left.\Delta t\right|_{(t)}}{2} \ddot{u}\right|_{(t)}
$$

Where $\mathrm{t}$ is time. The displacement at the end of the incremental step is determined based on the integration of speed over time plus and the displacement at the beginning of the increment step:

$$
\left.u\right|_{(t+\Delta t)}=\left.u\right|_{(t)}+\left.\left.\Delta t\right|_{(t+\Delta t)} \dot{u}\right|_{\left(t+\frac{\Delta t}{2}\right)}
$$

ABAQUS/Explicit analysis steps and the software modules used in each step are shown in the Figure I.

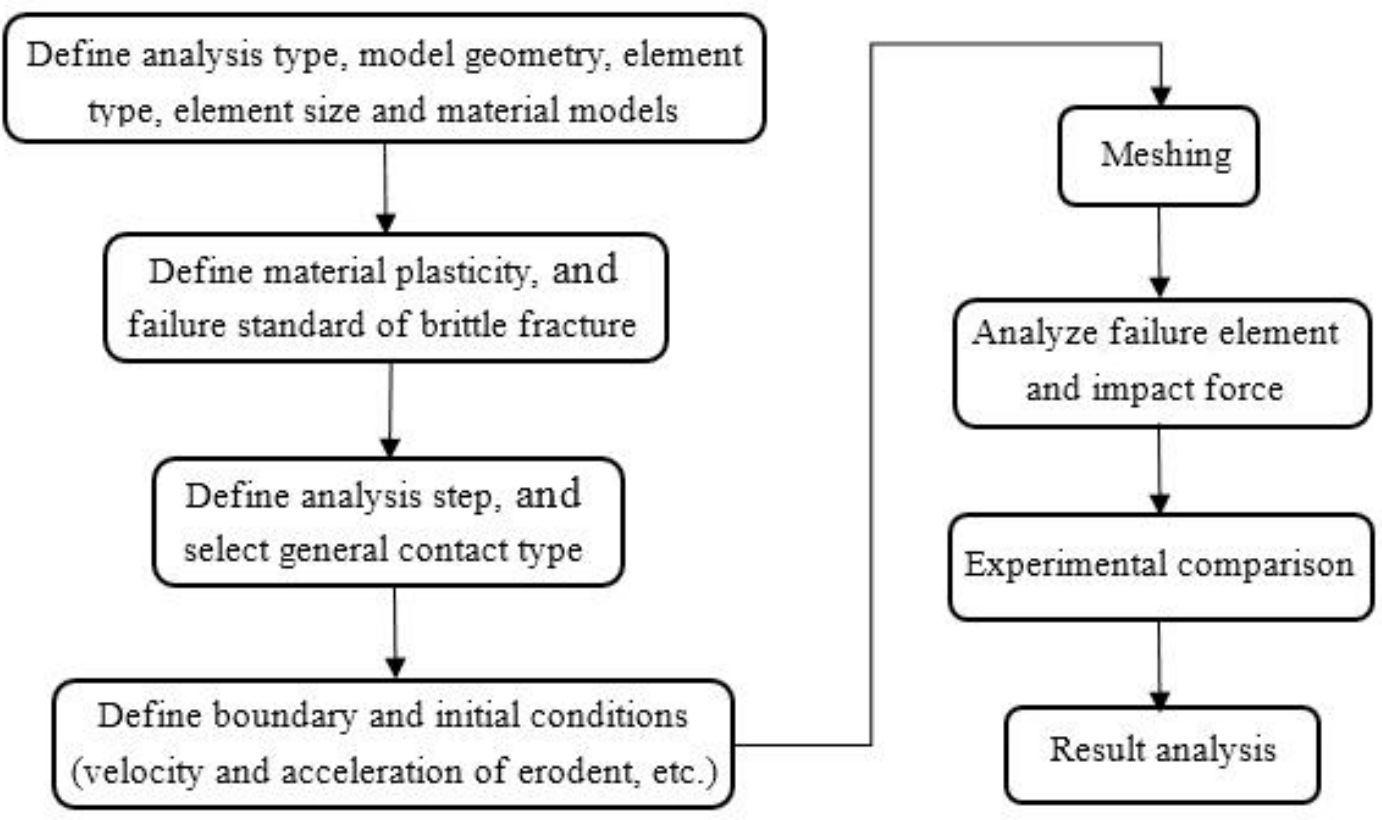

FIGURE I. EROSION MODEL SOLUTION FLOW DIAGRAM

\section{B. Model Definitions and Material Properties}

In the ABAQUS FE model, dynamic-explicit was used. The 8-noded, 3D solid brick element SOLID164 was used to describe both the substrate and coating. Erosion particles are constrained to rigid bodies in the interaction plate. In order to minimize the computational cost without compromising the accuracy of the calculations, it is essential to optimize the geometry and the element size of the calculation domain. Finally, the erosion model used in this study is presented in Table II.
TABLE II. STYLES EROSION MODEL

\begin{tabular}{|l|l|l|}
\hline \multicolumn{1}{|c|}{ Variable } & \multicolumn{1}{c|}{ Unit } & \multicolumn{1}{c|}{ value } \\
\hline $\begin{array}{l}\text { Coating } \\
\text { thickness }\end{array}$ & $\mathrm{mm}$ & 2.5 \\
\hline $\begin{array}{l}\text { Substrate } \\
\text { thickness }\end{array}$ & $\mathrm{mm}$ & 120 \\
\hline Erosion particle & $\mathrm{mm}$ & 100 \\
\hline Erosion angle & $\mathrm{deg}$ & 90 \\
\hline Erosion rate & $\mathrm{m} / \mathrm{s}$ & 100 \\
\hline
\end{tabular}


In the FE model, the nitride coating material model uses an isotropic linear elastic material model. However, in order to simulate the wear of the coating surface during erosion operation and calculate the erosion rate of the coating, the material failure criterion is additionally defined. Nitride coating is a typical brittle material. Generally speaking, tensile failure is used as the criterion damage. Use the keyword editor feature to add keywords to define the material's tensile failure properties. When the tensile stress exceeds the tensile strength limit of the material, the material begins to fail. A unit's mass, stiffness, stress and strain are set to zero (or very close to zero), causing it to play a role in the overall calculation no longer. The failed unit will be removed from the finite element mesh model so that the wear of the material can be visually observed in post-processing.

\section{Analyze Steps and Contact Properties}

Because of the unique nature of the erosion process, the dynamic analysis step was used as the analysis step select. It is given in the above formula. ABAQUS/Explicit explicitly derives the solution of the dynamic equilibrium equation from the static state of the previous incremental step rather than iteratively solving the contact. The ABAQUS/Explicit solution has a large number of incremental steps. However, because of the no need to solve the entire system of equations. The calculation cost of each incremental step is very small and the efficiency of solving complex nonlinear problems is very high.

The contact type of erosion problem is one of the most difficult nonlinear problems. The selection of contact types and algorithms is crucial to the analysis of contact problems ${ }^{[7]}$. In the erosion wear simulation, the contact between the abrasive particle and the target is defined and no contact is defined between the particles so that the particles can pass each other without contact collision. Universal contact is used in the ABAQUS between the abrasive particles and the target ${ }^{[8]}$. This type of contact ensures that in the event of material failure of the target, contact can still be performed in the remaining cells. When studying the effect of friction coefficient on the residual stress of the target, it was found that the change of residual stress and plastic strain of the target is not obvious as the friction coefficient varies in low range. The effect of the friction coefficient in this range is negligible. Therefore the friction coefficient between the abrasive particle and the coating is selected as 0.2 in this paper.

Surface-to-surface contact is used in the substrate and the coating. The contact model in ABAQUS/Standard is based on surface or contact based units and the constitutive model that controls the interaction between the contact surfaces is defined.

\section{COMPARISON OF THE NUMERICAL AND EXPERIMENTAL RESULTS}

In this FE simulation, the erosion wear rate of the three coatings was calculated from the number of failures of the unit time. Then the calculated erosion wear rates of the four coatings were used to analyze the influence of elastic modulus and hardness of the coatings . There are two major erosion wear mechanisms in the erosive wear of materials, including the plastic erosion wear of materials removed by cutting and the brittle erosion wear of materials removed by cracking. According to the definition, hardness is the ability of the material to resist plastic deformation or penetration of foreign objects under external load. High hardness can reduce the penetration depth of high-speed solid particles. Therefore, it can be theoretically derived that the high hardness of the coating can reduce the erosion wear of the material by cutting and reduce the erosion wear rate of the coating. However, in the actual results and simulations in Figure II, the erosion wear rates of the three different coatings did not completely decrease with increasing hardness.

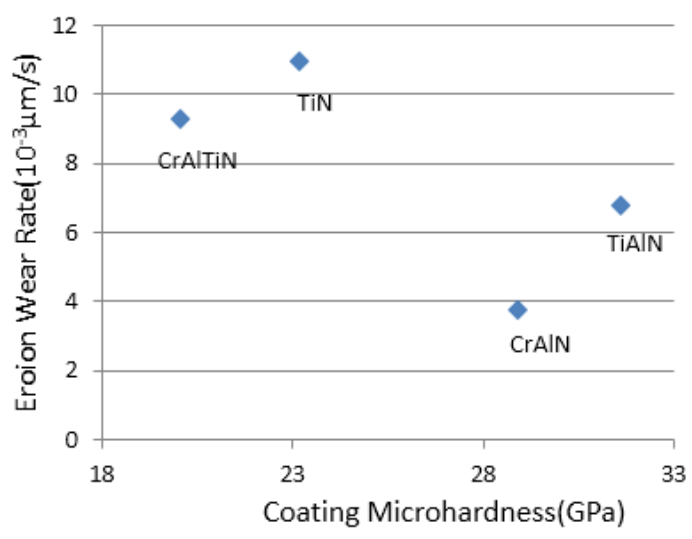

FIGURE II. COATING EROSION WEAR RATE

Toughness is the ability of a material to resist bending, impact, or torsion without cracking. Good toughness of the coating reduces the amount of erosion wear removed by cracking. It can be inferred that coatings with both high hardness and high toughness will have better erosion wear resistance. However, it is well known that measuring the toughness of thin coatings is very difficult. The mechanical properties of the coating's hardness $\mathrm{H}$ and elastic modulus $\mathrm{E}$ affect the deformation of the coating in an all-round manner. Shtansky ${ }^{[9]}$ believes that $\mathrm{H} / \mathrm{E}$ represents the ability of the material to resist long-term elastic strain. The value of 1 in Musi ${ }^{[10]}$ thinks that the value of $\mathrm{H}^{3} / \mathrm{E}^{2}$ represents the ability of the material to resist plastic deformation.

Figure III shows the erosive wear rate of the four coatings as a function of the $\mathrm{H} / \mathrm{E}$ value of each coating. It can be seen from the figure that the erosion wear rate of the coating decreases with increasing $\mathrm{H} / \mathrm{E}$ value, and the relationship between the two can be expressed by the following equation:

$$
E r \propto(H / E)^{-n}
$$

Where $n$ is a constant greater than 0 , it is a constant determined by both the coating properties and the matrix properties. The $\mathrm{H} / \mathrm{E}$ value can describe the erosion resistance of the nitride coating, which also indicates that the erosion wear of some of the coating materials of these coatings is due to the destruction of the elastic strain under the multiple impacts of the impact particles. 


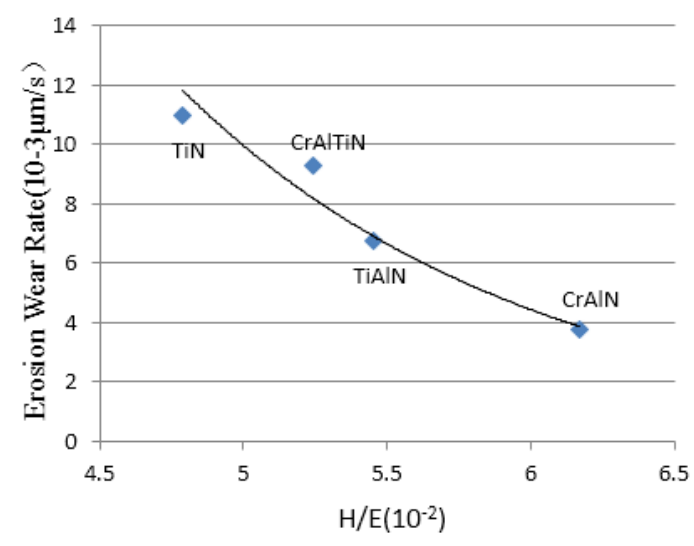

FIGURE III. COATING EROSION WEAR RATE AND H/E

Figure IV shows the erosion wear rates of the four coatings as a function of the order of the value of each coating. It can be found that the erosion wear rate of the coating decreases with the increase of $\mathrm{H}^{3} / \mathrm{E}^{2}$, and there is a certain functional relationship between the erosion wear rate of the coating and the $\mathrm{H}^{3} / \mathrm{E}^{2}$. It can be concluded that the $\mathrm{H}^{3} / \mathrm{E}^{2}$ value can describe the erosion wear of part of the coating material of the nitride coating as a result of the plastic strain failure caused by multiple impacts of the impact particles. The model was verified by the measured erosion rate of the four coatings on the same substrate. Erosion wear results showed the same result.

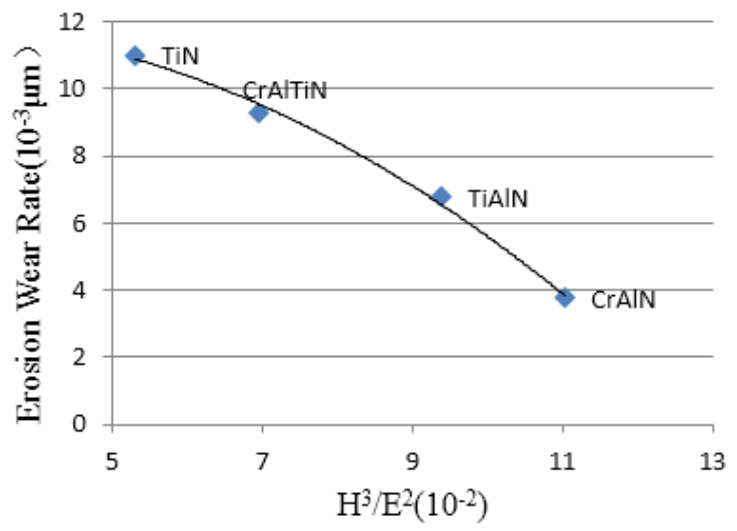

FIGURE IV. COATING EROSION WEAR RATE AND H ${ }^{3} / \mathrm{E}^{2}$

\section{CONCLUSION}

The use of nitride coating materials is one of the effective ways to improve the erosion resistance of the material. It is of great practical significance to study the erosion wear performance of nitride coating materials. In this paper, the erosion wear properties of nitride coating materials were studied by finite element simulation and experimental research methods. The main conclusions are as follows;

(1) The effect of the mechanical properties of the coating on the erosion wear performance was deduced. The hardness of the coating does not affect the erosion wear rate of the coating alone. It is combined with the elastic modulus $\mathrm{E}$ of the coating to affect the erosion wear rate of the coating. As the $\mathrm{H} / \mathrm{E}$ and
$\mathrm{H}^{3} / \mathrm{E}^{2}$ values increase with the decreases of erosion wear rate of the coating. This means that the coating's erosion resistance improves.

(2) The order of the erosion wear rate of the four coatings on the $\mathrm{WC} / \mathrm{Co}$ substrate from low to high is CrAlN $<$ TiAlN $<$ CrAlTiN $<$ TiN, in which CrAlN coating erosion wear rate is $1 / 3$ of TiN coating.

\section{ACKNOWLEDGMENT}

This work was supported by grants from Natural Science Foundation of Shandong province (No: ZR2015EM039). The authors would like to acknowledge the Clean Mechanical Manufacture (Shandong University) Ministry of Education.

\section{REFERENCES}

[1] Tabakoff. W, "Protection of coated superalloys from erosion in turbomachinery and other systems exposed to particulate flows," in Wear s 233-235.1,1999, pp.200-208.

[2] V.R. Paramesvaran, D. Nagy, J.P. Immarigeon, D. Chow, D. Morphy, Erosion resistant coatings for compressor applications, in: A.K. Koul, V.R.Paramesvaran, J.P. Immarigeon, W. Wallace (Eds.), Advances in High Temperature Structural Materials and Protective coatings, (Publication from National Research Council of Canada, Ottawa, 1994, pp. 262-281.

[3] Chen. Q and D. Y. Li, "Computer simulation of solid particle erosion," in Wear, vol 254.3-4, 2003, pp.203-210.

[4] Fengfang Wu, "Erosion wear performance and mechanism of PVD nitride coatings," Ph.D. thesis, Shandong University, 2011.

[5] Musil J, "Hard and superhard nanocomposite coatings," in Surface \& Coatings Technology, vol 125.1,2000, pp. 322-330.

[6] Smojver, I., and D. Ivančević. "Bird strike damage analysis in aircraft structures using Abaqus/Explicit and coupled Eulerian Lagrangian approach," Composites Science \& Technology, vol 71.4, 2011,pp 489498.

[7] Giner, E Giner, E., Sukumar, N., Tarancón, J. E.and Fuenmayor, F. J. "An Abaqus implementation of the extended finite element method," in Engineering Fracture Mechanics vol 76.3, 2009, pp 347-368.

[8] Meo, M, and R. Vignjevic. "Finite element analysis of residual stress induced by shot peening process," in Advances in Engineering Software 34.9, 2003, pp 569-575.

[9] Shtansky, D. V., Kiryukhantsev-Korneev, P. V., Bashkova, I. A., Sheveiko, A. N. and E. A. "Multicomponent nanostructured films for various tribological applications," in International Journal of Refractory Metals \& Hard Materials vol 28.1,2010, pp 32-39.

[10] Musil, J., and J. Vlček. "Magnetron sputtering of hard nanocomposite coatings and their properties," in Surface \& Coatings Technology vol $142.01,2001$, pp 557-566. 